\title{
VERBAL DISAGREEING STRATEGIES IN DETECTIVE CONAN MOVIE SERIES
}

\author{
Himmatul Maratis Suroiya ${ }^{凶}$, Novella Dara Adista, Indra Fuji Rahayu, Fadilla Nuzulul \\ Romadhoni, Nur Azizah, Zuliati Rohmah \\ UIN Sunan Ampel Surabaya \\ \oiyasoraiya@gmail.com
}

\begin{abstract}
This study is meant to investigate the ways of male and female criminals express types of verbal disagreeing strategies in Detective Conan movie series. To collect the data, 30 criminals (15 males, 15 females) were selected among hundreds of criminals appeared in the movie. The criminals were expected to disagree with 6 chosen interlocutors when they do debate over the accusation pointed to the criminals. The types of disagreeing strategies which help the researcher to analyze the disagreeing strategies in criminals are based on Muntigl and Turnbull taxonomy (in Behnam\&Niroomand, 2011:208). Qualitative content analysis is chosen to examine the criminals' disagreeing strategies. The results show that male criminals performed more disagreeing strategies by applying 56 disagreements, and female criminals applied 48 disagreements. From those disagreements, it is found new types of disagreeing strategies in addition to the types from the taxonomy of Muntigl and Turnbull (in Behnam \& Niroomand, 2011:208)
\end{abstract}

Keywords: disagreeing strategies; criminals; Detective Conan movie series

\section{INTRODUCTION}

Disagreement is unavoidable in human interactions. It is so hard to deny that people have different thought towards issues in some social interactions (Sofwan \& Suwignyo, 2011:42). They can disagree over a particular subject matter including objects or personal traits (Hei et al., 2012:2). According to Kozcogh (2013), disagreement is one of the most generally occurring speech events in everyday interactions. It can be seen through the factors drawn by Kozcogh (2013) from the growing popularity of disagreement as a research subject among linguists. Numerous researchers have been interested in doing study about disagreement such as studies in academic setting and studies in outside of academic setting. However, criminals' utterances are not yet to be investigated by the previous researchers. The present study analyzes the types of disagreeing strategies applied by criminals.

Most of previous studies on disagreements have been done in academic setting. As stated by Choyimah and Latief (2014:113) disagreement is one of speech acts that commonly take place in academic settings. It is proven by the studies from Sofwan and Suwignyo (2011), 
Behnam and Niroomand (2011), Rohmah (2012), Kozcogh (2012), Kozcogh (2013), Faharani and Molkizadeh (2013), Pattrawut (2014), Bavarsad et al. (2015), Aisyah (2015), Nourozi (2015), and Heidari et al. (2015). All of the researchers analyzed disagreements in students'sor learners' utterances, but some of them used different issues related to the disagreement such as power or status and gender.

Recently, the area of study about disagreeing strategies in movie or film outside the academic setting has received special attentions from various researchers in different movies and focuses. They are Carolina (2001), Panic-Kavgic (2013), Tifani (2015), and Arofah (2015). Most of those researchers studied American movie. None of those researchers analyzed disagreements in Asian movie. Detective Conan analyzed in the present study is one of Asian animation movie series that comes from Japan. It is one of the famous movies and has been shown since 1996. It has more than eight hundred episodes with hundreds of criminals who are involved in murderer, arson, and kidnapping cases. The criminals always make debates in solving episodes with the chosen interlocutors. Various verbal disagreeing strategies are applied by them to deny the accusation.

Detective Conan actually has been analyzed by some previous researchers. They are Anugramatur (2013) focusing on the types of speech functions uttered by Conan Edogawa, and Rahman (2015) focusing on the types of illocutionary act performed by the characters. None of those researchersfocus on disagreementsor disagreeing strategies. This study analyzes verbal disagreeing strategies in criminals' utterances when they argue with their interlocutors. The researcher only focuses on the disagreeing strategies when criminals debate over the accusation, not on a refusal. Since, refusal has its own and different area from disagreement.

Chen in Bella (2011:1719) stated that a refusal is a speech act that occurs when a speaker tries to deny to be involved in an action proposed by the interlocutor. The refusal can occur in criminals' utterance when they refuse to be asked to go to jail, not when they debate with the detective over the accusation or detective's deduction. Since, in the debate, they only try to disagree with the truth of their crime explained or proposed by the detective. They try to make the detective's deduction seen as an untrue fact, as Rees-Miller's (2000) arguments that disagreement occurs when a speaker considers the proposition uttered by the prior speaker is untrue.

Hence, in the present study the researcher is interested in investigating various disagreeing strategies applied by the criminals. The finding from this study is expected to be 
able to give pictures of how a criminal defends him/herself by uttering disagreements when someone gives an accusation and tries to reveal his/her criminal actions.

\section{REVIEW OF LITERATURE}

There are many ways which can be used in expressing feelings. One way to express the feeling of discontent with others is by expressing disagreement. Disagreement is a speech activity that is used to express different opinion from his/her interlocutor. Hence, it can be said that the speaker makes an expression of disagreement when she/he has different opinions from his/her interlocutor. The speaker tends to express it in order to achieve his/her purpose. It usually can be identified from its verbal structure which shows a different view from the preceding talk (Sofwan \& Suwignyo, 2011:42).

Disagreements can be used for a culprit or criminal to deny the accusation pointed by the interlocutor toward him. He wants to keep their save position to cover their crimes. He does not want to lose from the debate over the accusation. As stated by Sofwan and Suwignyo (2011) that disagreement is expressed as speech act activity in which the speaker try to keep their own positions by opposing the interlocutors. Disagreement can be expressed in some ways. Muntigl and Turnbull (in Behnam\&Niroomand, 2011:208; Sofwan\&Suwignyo, 2011:43-44) proposed some types of disagreeing strategies. There are 5 different types of disagreeing strategies identified. They are irrelevancy claim, challenge, contradiction, counterclaim, and contradiction followed by counterclaim.

Muntigl and Turnbull identified the taxonomy of the types of disagreeing strategies in 1995, but there were only 4 types identified (Behnam\&Niroomand, 2011:208). Irrelevancy claim, challenge, contradiction, and counterclaim were firstly identified by them. Irrelevancy claim is types of disagreeing strategies that the speaker seem to be questioning or undermining their interlocutors' previous claim by stating the previous claim is not relevant to the discussion of the topic at hand (Muntigl and Turnbull in Sofwan \& Suwignyo, 2011:43; Behnam \& Niroomand, 2011:208). The speaker asserts that the previous claim is not relevant to the discussion because the hearer is not in a specific view of what is being argued about (e.g. What are you talking about?).

Challenge, as the second type, typically has syntactic form of interrogative with question particles such as when, what, who, why, where, and how; they implicate that the addressee cannot provide evidence for speaker's claim (Muntigl and Turnbull in Sofwan \& Suwignyo, 2011:43; Behnam\& Niroomand, 2011:208). In expressing a challenge, the speaker questions an addressee's prior claim, demands that the addressee provide evidence for his/her claim, and 
at the same time suggeststhat the addressee cannot do so (e.g. What is the evidence that prove me as the culprit?).

In the third type that is contradiction strategy, a speaker contradicts the interlocutor by uttering the negated proposition expressed in the previous claim: that is, if A utters $\mathrm{P}$, then B utters $\sim$ P (Muntigl and Turnbull in Sofwan \& Suwignyo, 2011:43-44). As Behnam and Niroomand (2015:208) stated that contradictions often occur with a negative particle such as no or not, as in No, I don't. It indicates that the prior claim is not true (e.g. I didn't kill him). However, Chen in Aini (2015) stated that contradictions are not always preceded by a negation, but it also occasionally starts with contradictory statement, such as "I thought it was so boring."

In expressing disagreement by using counterclaim, the speaker's emphasis is not on pure opposition such as irrelevancy claim, challenge, or contradiction strategy. The speaker provides an alternative claim and/or reason for why she/he disagrees, which invites negotiation of the previous claim by opening up the topic of discussion rather than closing it down (Muntigl and Turnbull in Behnam \& Niroomand, 2011:208). Sadrameli and Haghverdi (2016) stated that counterclaims tend to be preceded by pauses, prefaces, and mitigating devices like "Maybe you are right, but..." it is used to indicate indirectness and being polite in the speech act of disagreement (e.g. Yes, I got it. But we should go to the murder scene first).

In 1998, Muntigl and Turnbull proposed that there is a fifth type existing in disagreeing strategies. It is formed from the combination of contradiction and counterclaim (Behnam \& Nirooman, 2011:208). It is named as contradiction followed by counterclaim. The taxonomy is completed with 5 types of disagreeing strategies.In this type, the speaker begins the disagreement by contradiction then she/he continuous with a counterclaim that provides a reason for why she/he disagrees to the interlocutor (e.g. I don't think so, because everyone who is here can do it).

Some previous studies about disagreements were done by usingMuntigl and Turnbull taxonomy to analyze the disagreeing strategies. Most of those studies were conducted in academic setting. The researchers related some issues toward disagreeing strategies performed by the students. Behnam and Niroomand's study (2011) investigated the ways power relations influence politeness strategies in disagreement. In order to find out whether and to what extent the realization of the speech act of disagreeing and the of appropriate politeness strategies by Iranian EFL learners, in a university setting, across different proficiency levels (intermediate and upper-intermediate) differ in relation to people with different power status, a Discourse Completion Test (DCT) was completed by 40 Iranian EFL learners. The learners were placed 
at two different levels based on their scores on a proficiency test. The findings of the study provide some evidences for the relation between the learners' level of language proficiency and type and frequency of disagreement and choice of politeness strategies associated with people with different power status.

A study from Nourozi (2015) investigated the influence of politeness strategies in different disagreement situationsby Iranian learners of English as a foreign language. The sample involved 50 Iranian studentsInstitute. They were divided equally into intermediate and advance group. The findings of the study revealed that disagreement strategies are related to skills of language, EFL learners acquire pragmatic and linguistic knowledge. The major findings of this research that, intermediate and advance learners use the same type of strategies, however, they differ in the type and frequency of use of these strategies.

Bavarsad et al. (2015) analyzed the ways in which the speech act of disagreement is expressed by young male and female Persian speakers. The focus of the study was on the role that gender and power might play in the employment of strategies to mitigate the threat of disagreement. The results revealed that although both males and females were concerned about the power status of interlocutors and try to apply the appropriate strategies while expressing their disagreements, females were more cautious and used different strategies from those of males.

Those 3 previous studies have different focuses. Yet, there is one similar point which they have in their findings. The studies found all 5 types of disagreeing strategies from Muntigl and Turnbull taxonomy. Irrelevancy claim is also the fewest type used by the students/speakers in their studies. Favored types are taken by contradiction and counterclaim with the highest percentage among the 5 types of disagreeing strategies.

\section{RESEARCH METHODS}

The current research is a qualitative content analysis. Cole (1998) stated that content analysis is a method of analyzing written, verbal or visual communication messages. Content analysis allows the researcher to test theoretical issues to enhance understanding of the data. Through content analysis, it is possible to distil words into fewer content-related categories. Cavanagh (1997) also mentions that when classified into the same categories, words, phrases and the like share the same meaning.

The key instrument of the present study was the researcher herself. Therefore, the researcher spent a great deal of her time to read and understand the related theories and concepts before collecting and analyzing the data. The data in this analysis were in the form 
of the transcripts of movie series from Detective Conan movie. 30 criminals (15 males and 15 females) were selected based on good and long debate they have with the 6 chosen interlocutors. There are 4 male interlocutors, and 2 female interlocutors. The criminals' disagreement utterances were analyzed to find kinds of disagreeing strategies applied by male and female criminals. Percentages of each kind of the strategies were then counted.

\section{RESULTS AND DISCUSSIONS}

Based on the analysis, it is found 11 types of disagreeing strategies used by male criminals with the total of 56 times of occurrence. Meanwhile there are 9 types of disagreeing strategies used by female criminals with the total of 48 times of occurrence. The complete findings are shown in figure 1 and 2 as follows.

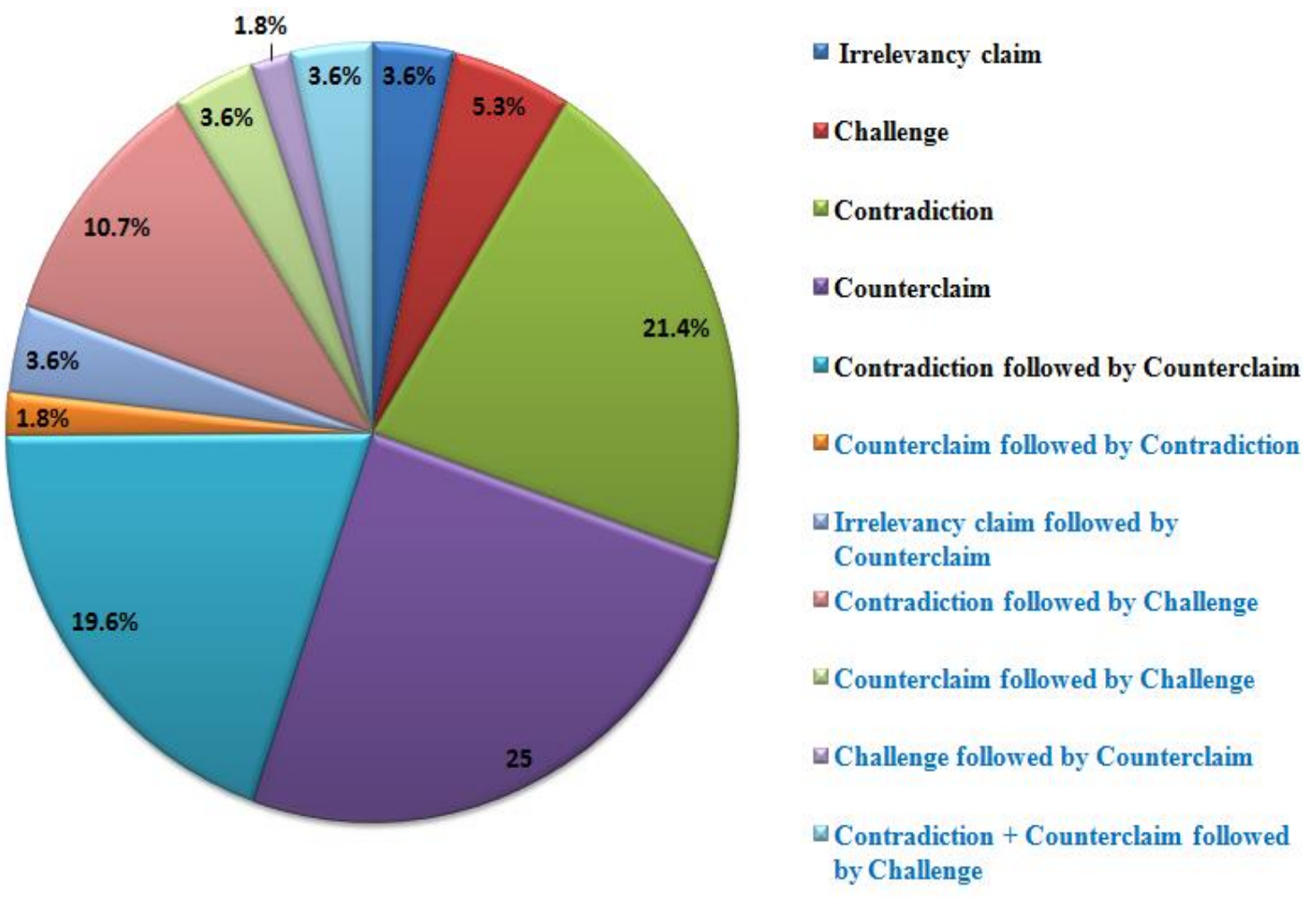

Figure 1: Male Criminals’ Disagreeing Strategies 


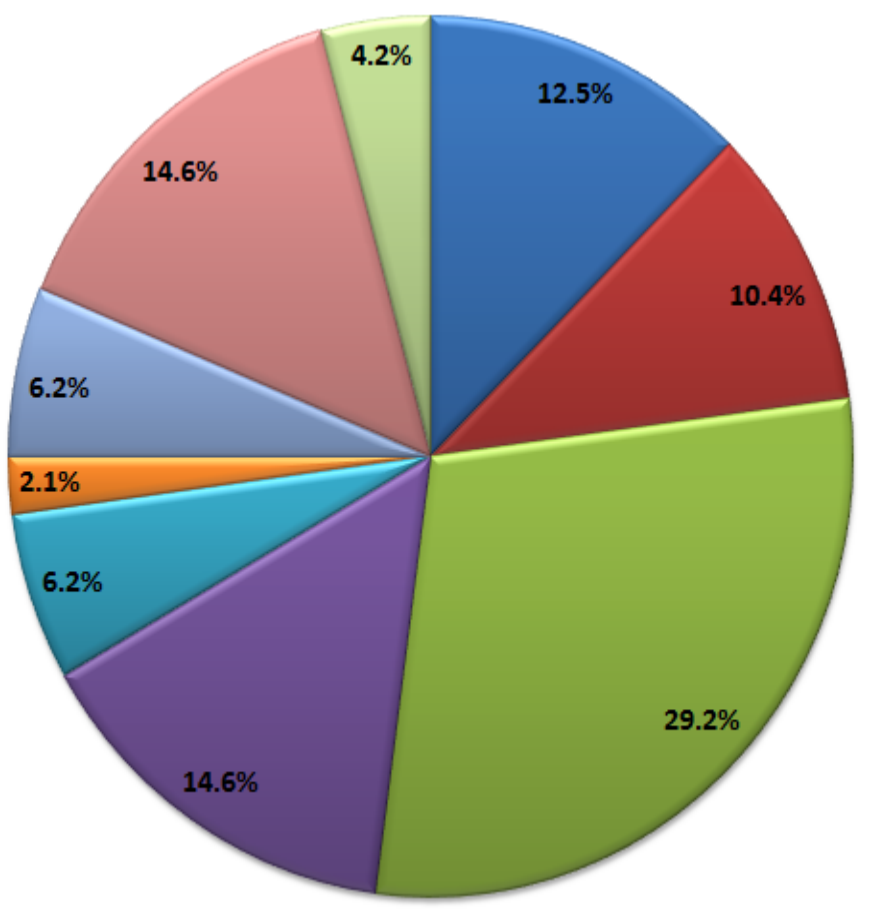

Challenge

Gontradiction

『 Counterclaim

Contradiction followed by Counterclaim

W Counterclaim followed by Contradiction

Irrelevancy claim followed by

Counterclaim

Contradiction followed by Challenge

Counterclaim followed by Challenge

Challenge followed by Counterclaim

Figure 2: Female Criminals' Disagreeing Strategies

Figure 1 presents the findings of types of disagreeing strategies from male criminals and Figure 2 presents female criminals' strategies. It was found 56 utterances containing disagreements and 11 types of disagreeing strategies in male criminals. Besides, in female criminals, it was found 48 utterances containing disagreements and 9 types of disagreeing strategies. Most of the disagreeing strategies have different percentages in both male and female criminals. 'Counterclaim' and 'contradiction' are favored type or have the highest percentage among male criminals' types of disagreeing strategies. The lowest percentage in male criminals is 'challenge followed by counterclaim'. Female criminals favor more on 'counterclaim' and 'contradiction followed by counterclaim'. They rarely used 'irrelevancy claim followed by counterclaim' in their disagreements. Each type of the disagreeing strategies from male and female criminals are elaborated below along with the example.

\subsection{Irrelevancy claim}

Irrelevancy claim is the type that will be chosen when the hearer is not in specific view of what is being argued in the discussion. He/she is questioning or undermining the previous utterance of the interlocutor. It seems that the interlocutor is straying off the topic. Male criminals use 'irrelevancy claim' in two utterances or 3.6\%. It can be seen inone of the data below. 


\section{Excerpt 1}

Officer : There is no doubt that this was merely an accident. Kurumatani-san, I'm going to take your statement regarding the accident.

MouriKogoro : Hold on. This is no ordinary accident, I think it's a premeditated murder case done by Kurumatani-san.

\section{Kurumatani Seiji: What are you saying all of a sudden?! [Eps.556/P.7]}

Kurumatani Seiji, a male criminal, uses 'irrelevancy claim' to disagree withMouri's utterance which states that the case is a premeditated murder case. Seiji seems shocked and he then questions Mouri's utterance, "What are you saying all of a sudden?!" Since, actually, the discussion about the case has almost drawn a conclusion that the case is an accident, and Seiji is also a victim. His statement is strengthened by the officer's statement. He also knows that the victim's car does not hit the brake indicating that the vicim does not notice the incoming car which makes the collison course phenomena as the reason of the accident. But Mouri suddenly states that it is not. Seiji does not agree directly and states the utterance containing 'irrelevancy claim' because he thinks that Mouri is straying off the topic all of a sudden by accusing him and stating that the case is a premeditated murder case. Especially, there is an evidence from the surveilance camera that there is no anything out of ordinary. The discussion is about the evidence of whether the accident is merely accident or not. When the proofs already show that the case is accident, even Mouri seems agree with it beforehand and the officer concludes that it is an accident. Yet, he suddenly states that it is a murder case where there is no possibility that it is.

\subsection{Challenge}

This second type of disagreeing strategies is found in both of male and female criminals' utterances. In fact, femalecriminals use it more than male criminals do. Female criminals' challenge reaches $12.5 \%$ or 6 times of the total amount of the data. Besides, male criminals' challenge reaches only $5.3 \%$ or 3 times of the total amount of the data.

As the name of the type shows, 'challenge' presents disagreeing strategies in a thoughtprovoking way. It represents the criminal's desire to unable the interlocutor to provide an evidence of his/her utterance or accusation towards the criminal. It shows that the criminals want to prove that they are innocent, since they are brave enough to give a challenge to the interlocutorbygiving a question. Therefore, it typically has syntactic form of interrogative with question particles such as when, what, who, why, where, and how.

Excerpt 2

Ueda Jouji : Please, wait a minute! When Yoshimura fell, I was right there with you Mouri-san, wasn't I? 
MouriKogoro: That's true. You used me to create an alibi.

Ueda Jouji : But how would it be possible for me to make Yoshimura fall if I was with you? [Eps.232/P.3]

Ueda states a challenge by asking how he can kill the victim when he has an alibi. He expects that the interlocutor will not be able to answer that question to prove that he is innocent. He is brave to ask because he has his alibi.

\subsection{Contradiction}

With $21.4 \%$, contradiction has the second highest frequency among male criminals' disagreeing strategies. The exact amount is 12 utterances. While femalecriminals' contradiction only reaches a half of male criminals' percentage that is $10.4 \%$ with the exact amount is 5 utterances. Contradiction occurs with a negative particle such as no or not.

\section{Excerpt 3}

Mouri Kogoro: No. In order to prevent the hole from being found, you had to break the glass.

Katsugi Kensuke: That's not true. [Eps.512/P.6]

In excerpt 3, there is particle "not" in the utterance of the criminal named Katsugi Kensuke. He disagrees with Mouri's claim by saying "That's not true" as he contradictsMouri's accusation. He makesMouri's claim appear to be wrong or misguided by uttering that Mouri's thought is not true.

\subsection{Counterclaim}

This type reaches the highest frequency not only among male criminals but also among femalecriminals. Both male and femalecriminals reach the same amount of frequency, but different in the amount of percentage. That is 14 times or $25 \%$ for male criminals, and 14 times or $29.2 \%$ for femalecriminals.

\section{Excerpt 4}

Mouri Kogoro : Something as trivial as this can be done by anybody.

Saneto Shishido: All right, even if what you said was true, but I have an alibi, and it's a perfect alibi.

Mouri Kogoro: Yes. Besides the 3 minutes these children didn't see you.

Saneto Shishido:You can say that, but you can't do anything in $\mathbf{3}$ minutes.[Eps.109/P.2]

Counterclaim used by Saneto is presented with a preface to mitigate the disagreements. "All right, even what you said was true" and "You can say that" are partial agreement. He seems to agree at the first time, but then he continues by stating the statement started by "but" 
to imply his actual disagreements. Therefore, counterclaim is the type which can be considered as implied disagreement.

\subsection{Contradiction followed by Counterclaim}

This first combination type of disagreement that is between 'contradiction' and 'counterclaim'is produced 11 times by male criminals or 19.6\%. Meanwhile, female criminals use it in 7 times or $14.6 \%$. Even though it is a combination of 2 types, but the function of each types does not change. 'Contradiction' is to contradict the previous utterance, and 'counterclaim' is to give a reason or explanation of a fact to the interlocutor. But it is used in one time as a combination to be 1 type. And counterclaim here tends to appear without a preface, because there is a contradiction that is to start the disagreement.

\section{Excerpt 5}

Kudo Shinichi: The person who killed Tatsuya-san is you, his manager, Tarehara Marisan!

Terahara Mari : That's nonsense. Since when Tatsuya collapsed in this room, I was on the phone that's outside of this room.[Eps.42/P.19]

Terahara, a female criminal in excerpt 5 , directly disagrees by using 'contradiction' when she is accused as the culprit of the case. There is word "nonsense" to contradict Mouri's accusation. Then, her utterance is followed by 'counterclaim'. She presents a reason why she contradicts or disagrees and saying that Mouri's utterances are nonsense, that is she has an alibi when the crime happens.

\subsection{Counterclaim followed by Contradiction}

As its name implies, this type is the opposite of the previous type 'contradiction followed by counterclaim'. This $6^{\text {th }}$ type is 'counterclaim followed by contradiction'. In the previous type, the criminals contradict first and then give their reason, while in this type, the criminals present their reason or explain their argument by saying 'counterclaim' to perceive the interlocutor's claim and then continued by 'contradiction'. Considering the percentage, for male criminals, it is only $1.8 \%$ and the exact amount of it is 1 utterance. For femalecriminals, it is $6.2 \%$ with the exact amount of the frequency is 3 utterances.

\section{Excerpt 6}

Mouri Kogoro: The president loved being showy and would do things such as magic tricks or skits, and he couldn't stand sour things. So you proposed this to the president beforehand, right? Saying, "Everyone would be surprised if you ate the sour Spy Choco White without making a face!" or something like that. 
Urai Hosie : Just a few days ago, my husband ate a sour-flavored cake and bedridden as a result. There is no way he'd eat that chocolate.[Eps.609/P.16]

Ueda chooses to explain by telling a real fact of his husband who bedridden after eating a sour-flavored cake. She wants to tell the truth that proves his husband cannot eat the sour Spy Choco White. She, then, utters her 'contradiction' of Mouri's claim. She wants to make Mouri's claim appear to be wrong.

\subsection{Irrelevancy claim followed by counterclaim}

This $4^{\text {th }}$ combination type is produced in few numbers by the criminals. Considering the percentage, it is $3.6 \%$ and the exact amount of the frequency is 2 utterances produced by male criminals. For femalecriminals, it is only $2.1 \%$ and the exact amount of the frequency is just 1 utterance. Irrelevancy claim that is used to represent the questioning speaker about the sudden and irrelevant utterance uttered by the interlocutor is supported by counterclaim in this type. Counterclaim has function to emphasize that the interlocutor's statement is indeed irrelevant from his/her previous statement in the discussion.

Excerpt 7

Mouri Kogoro : The culprit was you, Maekawa-san! You actually didn't go to catch octopuses, did you? You quickly hid yourself near the private spa, and without him suspecting anything, you brained Umezu-san with the rock. Then, you forced his head under the water and drowned him.

Maekawa Kouichi :What are you talking about?! You and I heard the noise at 8:00 as well. You also said it before.[Eps.567/P.7]

What are you talking about?" is regarded as the way of Maekawa, a male criminal, to express that he is questioning over Mouri's statement which accuses him as the culprit. Moreover, the criminal already have a perfect alibi, and the interlocutor have accepted it beforehand. As Maekawa states in his 'counterclaim', he has his alibi since the noise is heard at 8:00. He presents his reason to disagree that he is accused as being the culprit. The counterclaim used for emphasizing his ‘irrelevancy claim' towards Mouri’s irrelevant claim.

\subsection{Contradiction followed by Challenge}

This type can be considered as a strong disagreement, since when a criminal already gives a'contradiction' to deny, he/she still continues by giving a 'challenge' to challenge the interlocutor's claim. For this type, male criminals tend to favor it more by producing 6 utterances or $10.7 \%$. Meanwhile, femalecriminals only produce a half of male's percentage that is 3 utterances or $6.2 \%$. 


\section{Excerpt 8}

Mouri Kogoro: The reason you held Yoshimura-san's corpse was to create an excuse to return here to change the furniture back. The reason Conan saw you sweating in your apartment was because you had just finished moving the furniture back.

\section{Ueda Jouji : That's nonsense! Do you have any proof?![Eps.232/P.2]}

In the excerpt above, Ueda gives a contradiction by stating a negative evaluation only. He states that Mouri's deduction is nonsense. The word 'nonsense' can be used to contradict. Since the criminal wants to make the interlocutor's statement appear to be nonsense story to be believed. Contradiction can start with contradictory statement such as a negative evaluation for the interlocutor's utterance, even though it appears without a negated proposition. Ueda continues his disagreement by challenging to ask whether Mouri has any proof. $\mathrm{He}$ challengesMouri whether he could show that his statement is true by showing the proof.

\subsection{Counterclaim followed by Challenge}

Counterclaim followed by challenge found in a big number in femalecriminals' utterances. There are 7 femalecriminals' disagreements which contain this $9^{\text {th }}$ type. It is equal to $14.6 \%$ from the entire data of female criminals' disagreeing strategies. Meanwhile, for male criminals, it is only found in few numbers that is 2 utterances or 3.6\%.In this type, counterclaim is used as opening of their disagreement to answer back or to be a preface of what they will say to disagree. In other words, it is like they disagree impliedly at first and then they disagree explicitly through ask a question to challenge the interlocutor.

Excerpt 9

Mouri Kogoro : Knowing that Soejima-san was an alcoholic, you created numerous situations where he might get himself accidentally killed. Then, all you had to do is wait, like sitting in a café terrace, drinking tea.

Takahata Kyouko: That's interesting!Your deduction is great, but there is a missing point. Do you have evidence that I am the culprit?[Eps.570/P.13]

TakahataKyouko, a Female criminal, uses 'counterclaim' with a preface. As she uttered in her first utterance, "That's interesting" is to give a positive evaluation over Mouri's deduction. It makes Mouri's deuction appears to be an interesting deduction. She even continues her sentence which states that Mouri's deduction is great. She seems like she acknowledges a possibility that Mouri's deduction is true. But, for sure, she then starts to show a disagreement by saying "there is a missing point". She continues by disagreeing explicitly. She asks a question that indicates the missing point she states before. She asks 
about the proof of Mouri's accusation which states that she is the culprit. She challenges whether Mouri has evidence.

\subsection{Challenge followed by Counterclaim}

Challenge followed by counterclaim is the opposite combination of the previous type. The criminals give 'challenge' at first, and then they give 'counterclaim' to strengthen their 'challenge'. They use 'counterclaim' to continue their 'challenge'. They present a reason to indicate that their question asked through 'challenge' cannot be answer easily. Only a few of the criminals' utterances consist of this type. For male criminals, there is only 1 utterance or $1.8 \%$. For femalecriminals, it is 2 utterances or $4.2 \%$. The only data of this type from a male criminal is presented below.

Excerpt 10

Mouri Kogoro : Well then, shall we experiment?

Imaoka Kuishirou: Wait a minute. Then when did I take out a boat? Large waves started coming in, so it was a stormy sea. A boat would just capsize, and there were no marks of a boat being draaged on the beach.[Eps.677/P.9]

When debating about evidence, Imaoka denies Mouri's idea through asking a question. He expectsMouri cannot answer it, since he continues his disagreement by proposing a counterclaim to strengthen his disagreement. He states that yesterday is stormy sea that makes a boat will capsize. He also proposes a fact that there is no a mark of a boat being dragged. It implies that he cannot bring a boat to the sea, as he states in his counterclaim. It makes his 'challenge' cannot be answered easily.

\subsection{Contradiction + Counterclaim followed by Challenge}

This last type is formed from a combination type and one type that are from the $5^{\text {th }}$ type and the $2^{\text {nd }}$ type. It is only found in male criminals' utterances. None of female criminals use it. Only a few of male criminals' utterances consist of this type. 2 utterances represent the use of this type. This is equal to $3.6 \%$. The criminals use it to disagree explicitly first by 'contradiction', and then they propose 'counterclaim' to show their reason or facts to support the 'contradiction'. They continue by making a 'challenge' to ask a question towards the interlocutor.

Excerpt 11

Prof. Agasa : Exactly, I did see it. At that time a strange food delivery person running without a delivery box, and what's more, the bottom part of his head that I was able to see under the cap was exactly the same inverted-V style as Satan-san's. 
Satan Onizuka: But there's no evidence there was that delivery person you talked about. And there are other people who have the same haircut as me. They could even have been one of my fans. Plus, if I murdered the president like that, how did I reapply this makeup after I came back here?[Eps.488/P.5-6]

A long disagreement expressed by Satan Onizuka as a male criminal in excerpt 11. Satan directly disagrees with Prof. Agasa's accusation through his contradiction that there is no evidence about the delivery person Prof. Agasa talks about. He wants to make Prof. Agasa appears to be wrong in seeing the delivery person. He continues his disagreement by stating 'counterclaim'. He explains a reason and a fact through it. He explains that there are other persons who have the same hair style as him, and the delivery person can be one of his fans. It implies that he cannot be the culprit if it is due to the hair style, since other people have the same hair as him. It also implies that it is not a strong evidence to accuse Satan as that delivery person. He does not stop there. He continues his disagreement again by stating 'challenge'. He asks if he is the culprit then how he will reapply his makeup.

All in all, from those 11 types of disagreeing strategies, there are 6 new types of disagreeing strategies found in this study beside 5 types from the taxonomy of Muntigl and Turnbull (in Behnam \& Niroomand, 2011:208). The new types can be seen clearly in figure 1 and 2. As stated in the review of literature, Muntigl and Turnbull completed the 5 types of strategies by proposing the $5^{\text {th }}$ type that is contradiction followed by counterclaim (Behnam \& Niroomand, 2011:208). It is the result from combining two previous types, contradiction and counterclaim which were identified before in 1995. These 6 new types in this study also come from the previous 5 types of disagreeing strategies in Muntigl and Turnbull taxonomy (in Behnam \& Niroomand, 2011:208). The results of the present study show that the combining types can be formed from other types such between challenge and counterclaim, or challenge and irrelevancy claim. The criminals in this study tend to combine the types. They want to make strong disagreement which cannot be denied easily by the interlocutor, since they really do not want their crime to be uncovered. Suryanto stated in Destiyani's study (2011:4) that criminals have different characteristics and thought than other people. They tend to be brave, expert in manipulating, and have more power. They are also weak in controlling emotion (Destiyani, 2011). In this study, the criminals are brave to always state their disagreements. It is proven by the new types which occur in this study. They are in dangerous situations which push them to state strong disagreement in order to keep their crime. If they state a weak disagreement which can be denied, their crime can be revealed by the detective. Therefore, they state a strong disagreement by combining 2 types of disagreeing strategies. 
The new types are also not found yet in previous studies. Some previous studies which used Muntigl and Turnbull taxonomy to analyze the disagreement did not show new types as in this study. The studies by Behnam and Niroomand (2011), Sofwan and Suwignyo (2011), Faharani and Molkizadeh (2013), Bavarsadet al. (2015), Heidariet al. (2015), Nourozi (2015), and Sadrameli and Haghverdi (2016) found all the 5 types in their study. The results of those previous studies only show the existence of the 5 types of disagreeing strategies. Hence, the 6 new types can be considered as the new result that can enrich the previous taxonomy.

\section{CONCLUSION}

In summary, there are 11 types of disagreeing strategies applied by male criminals, and 9 types applied by female criminals. From both male and female criminals' types of disagreeing strategies, it can be drawn a result that there are 6 new types found in totally. The new types can occur because the criminals tend to combine 2 types into 1 type. They tend to be brave to express their disagreements because they do not want their crimes to be revealed by the interlocutor. Hence, the new types appear in the present study.

Since this study only focuses on types of disagreeing strategies applied by male and female criminals, future studies can focus on disagreement in criminals by relating it to some issues, such as, power and gender. It can focus on the differences between male and female criminals in expressing the disagreements. Male and female interlocutors also existed in the Detective Conan movie series. It could be compared between male criminal and male interlocutor, male criminal and female interlocutor and so on.

\section{REFERENCES}

Aini, W. N. (2015). Realization of Disagreement Strategies by Indonesian Speakers. English Review: Journal of English Education, 3(2), 239-246.

Aisyah, A. S. (2015). Interlanguage Pragmatics of Disagreement by Indonesian EFL Learners. Publication Article, Muhammadiyah University of Surakarta.

Anugramatur, D. SP. (2013). Speech Function in the Comic Entitled "Detective Conan". (Thesis, Diannuswantoro University, Semarang).

Arofah, S. (2015). Verbal Disagreeent Strategies Used by Greg towards His Father and His Future Father-in-Law in "Meet The Fockers" Movie. (Thesis, UIN SunanAmpel Surabaya).

Bavarsad, S. S., Eslami-Rasekh, A. \&Simin, S. (2015). The Study of Disagreement Strategies to Suggestion Used by Iranian Male and Female learners. Journal of Pragmatics,49, 3042. Retrieved March 3, 2016 fromhttp://dx.doi:10.18052/www.scipress.com/ILSHS.49.30 
Behnam, B. \&Niroomand, M. (2011). An Investigation of Iranian EFL Learners' Use of Politeness Strategies and Power Relations in Disagreement across Different Proficiency. English Language Teaching, 4, 204-220. Retrieved March 3, 2016 from http://dx.doi.org/10.5539/elt.v4n4p204

Bella, S. (2011). Mitigation and politeness in Greek invitation refusals: Effects of length of residence in the target community and intensity of interaction on non-native speakers' performance. Journal of Pragmatics, 43, 1718-1740.

Carolina. (2011). The Study of Disagreement Between Characters in The Film Ten Things I Hate about You. (Thesis, Petra University, Surabaya)

Cavanagh S. (1997). Content analysis: concepts, methods and applications.Nurse Researcher, $4,5-16$.

Cole F.L. (1988). Content analysis: process and application. Clinical Nurse Specialist, 2(1), 53-57.

Choyimah, N. \& Latief, M. A. (2014). Disagreeing Strategies in University Clasroom Discussions among Indonesian EFL Learners.International Journal of Linguistics, 6(2), 132-152.Retrieved March 3, 2016 from http://dx.doi.org/10.5296/ijl.v6i2.5417

Destiyani, S. (2011).

FaktorKejiwaanSebagaiPendorongPelakuTindakPidanadanKaitannyadenganPenjatuhan VonisPidana. (Thesis, UIN SyarifHidayatullah, Jakarta).

Faharani, A. A. K. \& Molkizadeh, A. P. (2013). An investigation of Iranian Advanced EFL learners' Application of Politeness Strategies in Disagreement between Two Genders. Intenational Research Journal of Applied and Basic Sciences, 5(5), 628-633.

Heidari, A., Eslami-Rasekh, A. \& Simin, S. 2015. Politeness Strategies and Power Relations in disagreement. International Journal of Research Studies in Languange Learning, 4(2), $33-41$.

Hei, K. C., Meng. N. Y., Ling. W. N. \& Palaniappan. A. (2012). Gender Differences in Coping with Disagreements: Focus on Young Malaysians. Paper presented at Social Science Conference 2012, Bursa, Turkey.

Kozcogh, H. V. (2012). The Effects of Gender and Social Distance on the Expression of Verba; Disagreement Employed by Hungarian Undergraduate Students.(Doctoral dissertation,University of Debrecen).

Koczogh, H. V. (2013). The role of gender in verbal disagreement: A study of disagreement strategies employed by Hungarian undergraduate students. Gender Studies, 11(1), 229239.

Norouzi, M. (2015). Invesgating Politeness Strategies for Using Disagreements by Iranian EFL Learners at Different Proficiency Levels. 8(2), 89-102.

Panic-Kavgic, O. (2013). Patterns of Dispreffered Verbal Disagreement in Dialogues from American and Serbian Films. Jezikoslove, 445-459.

Pattrawut, C. (2014). A Cross-Cultural Pragmatic Study: Politeness Strategies and Realizations of the Strategies Used to Perform Student-Lecturer Multiple Disagreements 
by Native Speakers of Thai and English. Journal of Education and Social Research. 4(1), 147-158.

Rahman, R. (2015). An Analysis of Illocutionary and Perlocutionary Act in Detective Conan Comic. (Thesis, UIN SyarifHidayatullah, Jakarta).

Rees-Miller, J. (2000). Power, severity, and context in disagreement. Journal of Pragmatics, 32(8), 1087-1111.

Rohmah, Z. (2012). Promoting Harmony during Disagreements: A portrait of Adult Discussions in the Indonesian Context. Theory and Practice in Language Studies, 2(3), 440-449.

Sadrameli, S. M. H. \&Haghverdi, H. R. (2016). A Comparative Study of the Use of Disagreement Strategies among Iranian EFL Learners and Native Speakers of English. Journal of Applied Linguistics and Language Research, 3(6), 230-251.

Sofwan, A. \&Suwignyo, E. (2011). The Realization of Disagreement Strategies by NonNative Speakers of English. Language Circle; Journal of Language and Literature, 6(1). 41-56.

Tifani, D. N. I. (2015). Disagreement Strategies Used by Dre Parker as the Main Character in Karate Kid Movie. (Thesis, UIN Sunan Ampel Surabaya). 